\title{
Editorial on social technologies, videoconferencing, online and blended learning and modelling
}

\author{
Arthur Tatnall
}

Published online: 10 August 2013

(C) Springer Science+Business Media New York 2013

This final issue of EAIT for 2013 contains 8 articles, the first by Serhat Kurt from Turkey being titled: Examining teachers' use of computer-based technologies: A case study. This article presents a case study that illustrates the extent to which technology is used in and out of the classroom in the elementary schools of Turkey. The study showed that teachers' use of technology is very limited but those who do use it use it for administrative purposes, technology education, non-educational purposes, instructional preparation, teacher-directed instructional delivery, student homework and instructional assessment.

Enhancing primary school children collaborative learning experiences in maths via a $3 D$ virtual environment is an article written by Hara Bouta and Symeon Retalis from Greece. The article notes that over recent years there has been growing use of $3 \mathrm{D}$ virtual environments for educational purposes and that many studies advocate the integration of these environments into daily teaching practice. The paper presents an exploratory study in which collaborative learning strategies and cognitive apprenticeship models act as the pedagogical framework to facilitate learning and collaboration.

An article by Jared Keengwe, Emmanuel Adjei-Boateng and Watsatree Diteeyont from the USA: Facilitating active social presence and meaningful interactions in online learning, notes that online learning has minimized many barriers and constraints that are common in traditional learning environments, but that due to the absence of face-to-face contacts students and instructors are usually faced with the lack of active social presence and meaningful interactions. Their study's findings suggest need for online instructors to explore effective ways to design and facilitate active social presence and meaningful interactions in online learning.

In another article by Jared Keengwe, this time working with Jung-Jin Kang, both from the USA titled: Preparing in-service language teachers to design and implement technology-rich curriculum, the authors examine a technology-rich curriculum project that was implemented in China with in-service teachers during a three-year period. Their findings suggest the need to support in-service teachers to implement new technology-rich curriculum and also imply that curriculum designers need to have a good understanding of

\footnotetext{
A. Tatnall $(\bowtie)$

Victoria University, PO Box 14428, Melbourne 8001, Australia

e-mail: Arthur.Tatnall@vu.edu.au
} 
teachers of English as a Foreign Language in order to provide appropriate and relevant technology-rich curriculum.

Support options provided and required for modeling with DynaLearn-A case study by Rachel Or-Bach from Israel and Bert Bredeweg from the Netherlands notes that Science Educators advocate the importance of scientific modelling within science education, but that this a complex task involving integration of topics, 'languages' and abstraction levels requiring development of modelling skills. Their study explored how novice modellers use several support options while performing modelling assignments with DynaLearn — an intelligent learning environment for qualitative modelling.

Next follows a study by Chris Comber and Tony Lawson from the UK: Sustaining technological innovation: The example of videoconferencing in English Schools that explores the factors associated with technology integration and conditions which sustain technological developments. Their analysis identified critical dimensions associated with the sustainability of videoconferencing including technical and structural factors as well as policy frameworks and personnel status. The perceived usefulness and relevance of videoconferencing as a learning technology emerges as a central determinant of sustainability, with the conclusion that for policymakers and schools, videoconferencing has become an 'orphan' technology.

Building modern online social presence: A review of social presence theory and its instructional design implications for future trends was written by Guoqiang Cui and Barbara Lockee from the USA and Cuiqing Meng from China. The authors argue that among the factors that affect students' online learning experience, social presence is important due to the asynchronous nature of online learning and communication. Their paper reviews the origin and major definitions of social presence, documents arguments of its optimal amount and provides instructional design suggestions for the development of online social presence.

In the final article for this issue, Quantitative influence of HCI characteristics in a blended learning system, Poornima Nataraja and G. T. Raju from India point out the popularity of blended learning as an approach to training in India. In their article they describe a study to assess the effectiveness of Human Compute Interaction in blended mode for trainees. The evaluation provides an insight into levels of preference by trainees for human-human, human-computer and technology aspect of training.

As mentioned in my editorial for the last issue I would particularly like to see articles in future issues that discussed national policy issues, how these have developed and what effect they have had. Issues relating to the use of ICT with minority groups and developing countries would also be very welcome. The waiting time for publication for an article in EAIT is now about 12-15 months after acceptance, but because of their importance, articles of these types will be given preference. 